\title{
Pränatales Alpha-Fetoprotein und Neuralleistendefekte: Evaluation einer neuen Screening-Methode ${ }^{1}$
}

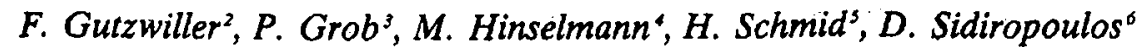

Der allfällige Nutzen einer Einführung des AlphaFetoprotein-Screenings in der Schwangerschaft wird in verschiedenen Ländern diskutiert, so auch in der Schweiz. Nach langen Vorarbeiten ist die Arbeitsgruppe für das AFP-Screening nun mit Hilfe eines vom Schweizerischen Nationalfonds finanzierten Forschungsprojektes in der Lage, in einer Studie die wissenschaftlichen Grundlagen zur Beantwortung der im Zusammenhang mit einem solchen Screening offenen Fragen zu erarbeiten.

Im vorliegenden Heft der «Sozial- und Präventivmedizin» finden sich die Beiträge zur Informationstagung «Alpha-1-Fetoprotein und Früherkennung von Neuralleistendefekten", welche am 12. März 1981 von der Arbeitsgruppe für das APF-Screening in der Schweiz (Präsident: Prof. H. Bossart, Lausanne) in Bern durchgeführt wurde.

Die Bestimmung des Alpha-Fetoproteins im mütterlichen Serum dient zur antenatalen Diagnostik von Dysrhaphien (Ánencephalus, Spina bifida, Meningomyelozele, Enzephalozele) und anderen Missbildungen. Alpha-Fetoprotein ist fetalen Ursprungs; es stammt aus dem endodermalen Gewebe. Die AFPKonzentration im mütterlichen Serum steigt von der 7. Schwangerschaftswoche bis zur 30.-32. Schwangerschaftswoche an. Für die antenatale Dysrhaphiediagnostik ist besonders der Abschnitt zwischen der 16. und 18. Schwangerschaftswoche wichtig. Die Zahl der Dysrhaphien liegt in Mitteleuropa bei $2 / 1000$, in den USA bei $2 / 1000$ und in England bei 3-9/1000 (davon Anencephalus $40 \%$ und Spina bifida $60 \%$ ).

Für ein Screening spricht die Tatsache, dass nur 10\% der Kinder mit Dysrhaphien in Familien mit belasteter Anamnese geboren werden. Dysrhaphiekinder stellen ein grosses medizinisches und soziales Problem dar. $50 \%$ der nichtanencephalen Kinder sterben innerhalb von 24 Stunden post partum, 50\% überleben. Von den überlebenden Kindern haben $75 \%$ ein schweres physisches Handicap, $20 \%$ zeigen eine mittelschwere bis schwere Retardierung. Zur Früherkennung dieser Missbildung wird das AlphaFetoprotein (AFP) zwischen der 16. und 18. Schwangerschaftswoche im Serum der schwangeren Frau bestimmt. Ist der Wert des AFP erhöht, erfolgt eine sofortige Wiederholung der Bestimmung sowie eine Ultraschallabklärung, durch welche andere Gründe für einen erhöhten AFP-Wert, wie zum Beispiel Mehrlingsschwangerschaft und falsch geschätztes Gestationsalter, erkannt werden können. Falls der Verdacht auf eine Missbildung nicht auszuschalten ist, folgen weitere klinische Abklärungen sowie eine Amniozentese und die Bestimmung des AFP in der Amnionflüssigkeit.

Unsere Kenntnisse über die medizinischen und auch psychologischen Auswirkungen der AFP-Überwachung von Schwangeren stammen vor allem aus England and Skandinavien, wo das AFP-Screening seit einigen Jahren weitverbreitet praktiziert wird. In vielen anderen Ländern wie Deutschland, Kanada und den USA ist erst kürzlich und erst an bestimmten Orten damit begonnen worden. Verschiedene Aspekte der AFP-Untersuchungen wurden in der "Schweizerischen medizinischen . Wochenschrift" 108, 1302 (1978), diskutiert. Die Arbeitsgruppe für das AFP-Screening, welche sich aus rund 20 Gynäkologen, Pädiatern, Neonatologen, Genetikern und Laborspezialisten aus allen Regionen der Schweiz zusammensetzt, versucht nun, während einer zeitlich beschränkten Untersuchungsperiode von zwei Jahren durch sorgfältige Dokumentation die positiven, aber auch die negativen Aspekte des AFP-Screenings in schweizerischen Verhältnissen $\mathrm{zu}$ bilanzieren. Zum Zweck der Studie werden mindestens 15000 Beobachtungen an schwangeren Frauen benötigt. Voraussetzung dazu ist die Mithilfe möglichst vieler Allgemeinärzte, Gynäkologen und Internisten, welche Schwangere betreuen.

Bis heute nehmen rund 100 praktizierende Ärzte an der AFP-Studie teil. Rund $\mathbf{4 0 0 0}$ Schwangere wurden registriert. Ziel bleibt die systematische Beurteilung der Vor- und Nachteile des Screenings zur Erarbeitung von Entscheidungsgrundlagen für eine eventuelle Einführung in der ganzen Schweiz.

\footnotetext{
${ }^{1}$ Kredit-Nr. 3.892.0.79, Schweizerischer Nationalfonds.

${ }^{2}$ PD Dr. med., Arbeitsausschuss AFP-Screening, Kantonsspital, 4031 Basel.

${ }^{3}$ PD Dr. med., Arbeitsausschuss AFP-Screening, Abteilung fulr Klinische Immunologie, 8044 Zürich.

'PD Dr. med., Arbeitsausschuss AFP-Screening, Ospedale «La Carità, 6600 Locarno.

'Prof. Dr. med., Arbeitsausschuss AFP-Screening, Institut für medizinische Genetik, 8032 Zürich.

'PD Dr. med., Arbeitsausschuss AFP-Screening, Abteilung für Perinatologie der Universitäts-Frauenklinik, 3012 Bern.
} 